\title{
Effect of Using Adjusted Parameters, Local and Global Optimums, for Phase Equilibrium Prediction on the Synthesis of Azeotropic Distillation Columns
}

\author{
Claudia Gutiérrez-Antonio, ${ }^{* \dagger}$ Andrea Ojeda-Gasca, ${ }^{\ddagger}$ Adrián Bonilla-Petriciolet, ${ }^{\S}$ \\ Juan Gabriel Segovia-Hernández, $\stackrel{\ddagger}{\ddagger}$ and Abel Briones-Ramírez ${ }^{\|}$ \\ ${ }^{\dagger}$ Facultad de Química, Universidad Autónoma de Querétaro, Cerro de las Campanas S/N, Las Campanas, Querétaro, 76010, Mexico \\ ${ }^{\ddagger}$ Departamento de Ingeniería Química, División de Ciencias Naturales y Exactas, Universidad de Guanajuato, Campus Guanajuato, \\ Noria Alta s/n, Guanajuato, 36050, Mexico \\ ${ }^{\S}$ Departamento de Ingeniería Química, Instituto Tecnológico de Aguascalientes, Av. Adolfo López Mateos \#1801 Ote., Fracc. Bona \\ Gens, Aguascalientes, 20256, Mexico \\ "Exxerpro Solutions, Av. del Sol 1B Interior 4B Col. El Sol, El Tintero, Querétaro, 76113, Mexico
}

\begin{abstract}
We analyze the effect of using adjusted parameters, corresponding to local and global optimums, in the NRTL thermodynamic model on the complete process synthesis (design, optimization and control) of homogeneous azeotropic distillation columns. The adjusted parameters that correspond to a global optimum were obtained with simulated annealing technique, while the adjusted parameters that correspond to a local optimum were taken from the Dechema Collection. Both sets of parameters were used to design a conventional sequence, a side-stream column, and a Petlyuk sequence. These designs were used as the initial solution to a multiobjective genetic algorithm with constraints handling, coupled to a processes simulator, where the number of stages and heat duty of each column were considered as objectives; as a result, a set of optimal designs, called the Pareto front, was obtained. Then, we chose some designs to analyze their theoretical control properties and the dynamic performance. Results show remarkable differences in structure, energy consumption, control properties, and dynamic performance of these schemes, depending on the use of adjusted parameters. The results show the importance of using the best adjusted parameters available, which in our case correspond to global optimums obtained with the simulated annealing technique.
\end{abstract}

\section{INTRODUCTION}

The separation of azeotropic mixtures is a difficult task due to the presence of azeotropes, which generates distillation boundaries in the composition space. The existence of distillation boundary in azeotropic mixtures restricts the feasible product separations for a given feed composition. ${ }^{1}$ Thereby, a key step in the design of azeotropic distillation columns is the choice of the thermodynamic model. At the same time, the thermodynamic model must reproduce the best the phase equilibrium both in all of the composition space and in the azeotropic points along with the distillation boundaries; ${ }^{2}$ to get this objective, the thermodynamic model must use proper adjusted parameters. Usually, the thermodynamic models employ adjusted parameters obtained from nonlinear regressions of the experimental phase equilibrium data; for instance, through the minimization of the difference between calculated and measured vapor fraction. In most of the cases, the objective function in nonlinear parameter estimation is nonconvex, and it may have multiple local optima. ${ }^{3}$ Therefore, assuming that experimental equilibrium data are thermodynamically consistent, it is clear that the use of different methods to realize the nonlinear regression will affect the resulting adjusted parameters, and, as a consequence, the predicted phase equilibrium. The high nonlinearity of the problem of parameters estimation suggests that only global optimization techniques should be used; however, in most of the cases, the estimation is based on a least-squares or maximum likelihood analysis. ${ }^{3}$ For instance, Gau et al. ${ }^{4}$ found that for some of the equilibrium data published in the Dechema Collection, the adjusted parameters are just local optima. This finding is very important, because design, simulation, optimization, and even control of the reactive and separation process rely on estimation of thermodynamic properties, especially the phase equilibrium. Even thermodynamic information is critical for the development and improvement of all chemical process technologies. 5 Thus, the calculation of adjusted parameters must be made with a robust technique for obtaining the global optimum, because the resulting parameters best fit the experimental data. The use of parameters that correspond to a global optimum then is more reliable, because it ensures that the phase equilibrium prediction is closer to the experimental data. Several works have been focused on studying the effect of the thermodynamic uncertainties on separate stages of the process synthesis, as will be detailed next.

In 1993, Reed et al. ${ }^{6}$ studied the effect of uncertainties in thermodynamic data and model parameters on calculated process performance. They found significant changes in the

Received: June 24, 2013

Revised: December 26, 2013

Accepted: December 29, 2013

Published: December 29, 2013 
process variables when reasonable uncertainties were applied to interaction parameters of an equation of state, in pure component and binary interaction.

Later, Vasquez and Whiting ${ }^{7}$ studied the effects of errors, both systematic and random, in the design and simulation of chemical processes; they estimated the adjusted parameters using regression methods. Their objective was identifying what kind of error is more significant in the process. In a later work, they analyzed the uncertainty and sensitivity of thermodynamic models in the design and simulation of industrial processes, using equal probability sampling approach. ${ }^{8}$ Also, in the same year, Xin and Whiting ${ }^{9}$ showed that the design of chemical processes is significantly sensitive to the parameter uncertainties.

Moreover, Xin et al. ${ }^{10}$ used the least-squares minimization approach to get kinetic parameters and binary interaction parameters. They weighted the minimization approach using experimental variances to get optimum parameters. Their results show that the use of experimental variances to weight the objective function does not necessarily generate optimum parameters, affecting the estimation of thermodynamic properties.

In 2004, Vidaurre et al. ${ }^{11}$ analyzed the robustness of nonlinear regression methods under uncertainty, in the estimation of parameter for kinetic models. The results show that the performance of regression procedures can be very sensitive to data uncertainty; this affects the validity of the parameters obtained, and also the estimation of thermodynamic properties. In the problem of reactive azeotropes, Doherty et al. $^{12}$ showed the effect of the uncertainty in the equilibrium constant of the reaction on different reaction schemes; this will affect the modeling of reactive and phase equilibrium of the mixture.

On the other hand, Gutiérrez-Antonio et al. ${ }^{2}$ studied the effect of using different thermodynamic models in the design of homogeneous azeotropic distillation columns; their results show that there are significant differences in the number of stages, even 87 stages. They suggested the use of NRTL model for estimation of phase equilibrium properties in azeotropic mixtures, both homogeneous and heterogeneous. The adjusted parameters used in the different thermodynamic models were taken from the Dechema Collection.

In 2009, Gutiérrez-Antonio et al. ${ }^{13}$ proposed the use of particle swarm optimization and simulated annealing to get adjusted parameters of NRTL solution model in homogeneous azeotropic mixtures. Despite that both methods are reliable for parameter estimation, it appears that the simulated annealing technique is the most suitable. Later, Bonilla-Petriciolet et al. ${ }^{14}$ used simulated annealing to calculate homogeneous azeotropes in reactive and nonreactive mixtures. They also concluded that simulated annealing is a robust strategy to calculate the global adjusted parameters in azeotropic mixtures with or without chemical reactions.

As can be seen, several works have focused on studying the effect of the thermodynamic uncertainties for the phase equilibrium calculation, on separate stages of the process synthesis (considering the stages of design, simulation, optimization and control). To our knowledge, no formal analysis has been made to study the effect of these uncertainties on the complete process synthesis, and knowing how these uncertainties passed from one stage to another. Moreover, no formal analysis has been made to study the effect that the use adjusted parameters, which can be local or global optimum, have on process synthesis. Usually, in the synthesis of chemical process, we select a thermodynamic model, taking a set of adjusted parameters; these thermodynamic data are used to design, simulate, optimize, and perform control studies to analyze a process from an integral point of view. The results give information about energy requirements, capital costs, and dynamic performance of the chemical process, and this information is used to make decisions about what sequences are feasible to implement. Thus, the adjusted parameters are of great importance, because they will affect the conclusions with respect to the feasibility of a chemical process. Therefore, the study of the effects that can be passed from one stage to another is very important, because it allows observing how the uncertainties can be enhanced and conducted to schemes with bad performance or elevated energy demand.

Thus, in this work, we analyze the effect of using adjusted parameters, which correspond to local and global optimum, for phase equilibrium calculation on the complete process synthesis of azeotropic distillation sequences. We select the NRTL model for phase equilibrium calculations of the selected azeotropic mixtures. The adjusted parameters, which correspond to a global optimum, for the NTRL model are calculated with the simulated annealing technique, because it has shown its high reliability in this kind of computations, ${ }^{13,14}$ while the adjusted parameters, which correspond to a local optimum, are taken from the Dechema Collection. Considering these two sets of parameters, we design a conventional sequence, a side-stream column, and a Petlyuk sequence for the separation of homogeneous azeotropic mixtures. The resulting designs are optimized through a multiobjective genetic algorithm with constraints handling, ${ }^{15}$ which is coupled to the Aspen Plus processes simulator; this ensures that all results generated consider the complete model of the distillation sequences. From the Pareto fronts generated, we selected some designs to analyze their theoretical control properties and dynamic performance. Results show remarkable differences in structure, energy consumption, control properties, and dynamic performance of these schemes, as a consequence of using global or local adjusted parameters.

\section{ESTIMATION OF ADJUSTED PARAMETERS}

The equilibrium between vapor and liquid phases in a $c$ multicomponent system implies that temperature, $T$, pressure, $P$, and the chemical potential of each component $i$ must be the same in both phases. At low pressure, the vapor-liquid equilibrium conditions can be simplified, because the fugacity coefficients of pure components nearly cancel each other, and Poynting corrections usually are very close to unity. Therefore, the vapor-liquid equilibrium, VLE, for a multicomponent system can be modeled with:

$$
\gamma_{i} x_{i} P_{i}^{\mathrm{o}}=y_{i} P \quad \text { for } \quad i=1,2, \ldots c
$$

where $\gamma_{i}$ is the activity coefficient of component $i, P_{i}^{o}$ is the vapor pressure of pure component $i$, and $x_{i}$ and $y_{i}$ are the equilibrium mole fractions at the liquid and vapor phase, respectively. Using eq 1 , the nonideal behavior is described solely by the liquid-phase activity coefficient. Therefore, the objective function commonly used for vapor-liquid equilibrium data modeling is given as: 


$$
F_{\mathrm{obj}}=\sum_{j=1}^{\text {ndat }} \sum_{i=1}^{c}\left(\frac{\gamma_{i j}^{\text {exp }}-\gamma_{i j}^{\mathrm{calc}}}{\gamma_{i j}^{\exp }}\right)^{2}
$$

where $\gamma_{i}^{\exp }$ and $\gamma_{i}^{\text {calc }}$ are the experimental and calculated values for the activity coefficient of component $i$, and ndat is the number of experimental data used for parameter estimation, respectively. This objective function weights the errors in small and large quantities equally during parameter estimation. In addition, the Dechema Collection employed this objective function for determining the adjustable parameters of thermodynamic equations for VLE data modeling. Therefore, eq 2 has been used for VLE data fitting and for comparison purposes with results reported in the Dechema Collection.

For the case of complete vapor-liquid equilibrium data (i.e., $x, y$ and $P$ at constant $T$, or $x, y$ and $T$ at constant $P$ ), excess Gibbs energy equations are widely applied for phase equilibrium. Given vapor-liquid equilibrium measurements and assuming an ideal vapor phase, the experimental values for the activity coefficients can be calculated from experiments and using eq 1 . There are several local composition models for the calculation of liquid-phase activity coefficients. Particularly, the NRTL equation is a flexible local composition model that can be used for the correlation of $\gamma_{i}$, and for representing complex vapor-liquid equilibrium behaviors in multicomponent systems. Note that this model usually offers a better performance for VLE data modeling than those obtained with UNIQUAC or Wilson equations. In fact, our preliminary calculations indicated that the NRTL equation is proper for modeling the thermodynamic behavior of systems used as case studies in this Article; it is worth mentioning that the approach presented in this work can be performed on other thermodynamic models.

For a binary mixture, the NRTL model has three adjustable parameters: parameters: $\mathrm{A} 12=g_{12}-g_{22}, \mathrm{~A} 21=g_{21}-g_{11}$, and the nonrandomness factor $\alpha_{12}=\alpha_{21}$; these parameters are estimated by minimizing eq 2 . Note that the third parameter $\alpha_{12}$ can be treated as adjustable, but several authors have suggested that it should be fixed between 0.2 and 0.47 . We will show that this choice is very important, due to that it may cause qualitative errors in the prediction of azeotropic states.

On the other hand, several studies have shown that the highly nonlinear form of local composition models makes the objective function in eq 2 nonlinear, potentially nonconvex with several local minima points within the specified bounds. Previous studies have shown that parameter estimation for vapor-liquid equilibrium involves the solving of a global optimization problem. ${ }^{4,16-18}$ In particular, the NRTL model, due to its flexibility, can predict more phases that actually exist in the system, if the parameter estimation procedure is not performed adequately. This qualitative discrepancy occurs more frequently in the vapor-liquid equilibrium modeling of azeotropic mixtures. ${ }^{18}$ Therefore, it is necessary to apply a suitable numerical strategy for reliably solving the parameter estimation in VLE modeling. In this study, we used simulated annealing for vapor-liquid equilibrium data fitting of binary systems using the NRTL equation.

Simulated annealing is considered a robust stochastic optimization strategy capable of solving global optimization problems, and it has found several applications in science and engineering, including thermodynamic calculations. Specifically, simulated annealing simulates the process of slow cooling of metals to achieve the minimum function value in a minimization problem. The cooling phenomenon is modeled by controlling a temperature-like parameter introduced with the concept of Boltzmann probability distribution. By a controlled temperature reduction as the algorithm proceeds, the convergence of the algorithm can be controlled. We have used the simulated annealing code developed by Goffe et al., ${ }^{19}$ which is based on the algorithm developed by Corana et al. ${ }^{20}$ Note that previous studies have reported a robust performance of simulated annealing for finding the global optimum solutions for VLE data modeling. ${ }^{13,16}$

Therefore, we use simulated annealing to estimate the adjusted parameters of NRTL solution model, through the minimization of eq 2 . Note that the formulation showed in eq 2 is equivalent to assuming that the standard error in the measurement of $\gamma_{i j}$ is proportional to its value. Herein, it is convenient to note that Esposito and Floudas ${ }^{21}$ have reported that the parameter estimation problem for VLE data modeling can be solved using a problem reformulation with convex underestimating functions and a branch and bound procedure. However, the problem reformulation and the development of convex underestimators is model specific. On the basis of this fact, the application of a black-box approach such as a stochastic optimization method is more proper for facing this parameter estimation problem, because this approach can be applied for any thermodynamic model and without any concern of the characteristics of the objective function. All experimental data are taken from the Dechema Collection. We use the following initial intervals for NRTL parameters in the global optimization of the objective function: A12, A21 $\in(-2000,5000)$ and $\alpha_{12} \in$ $(0.01,10)$. Note that these initial intervals have been defined using the results of previous studies, ${ }^{13,16}$ and they correspond to a wide search space for finding the global optimal solution of the parameter estimation problem.

\section{DESIGN OF DISTILLATION SEQUENCES}

Once both sets of adjusted parameters are available, we use them to calculate the residue curve map of the azeotropic mixtures and verify the feasibility of the separation. After the feasibility has been verified, the distillation sequences are designed.

The conventional distillation sequence is designed with the method of minimum difference in composition. ${ }^{22}$ In this method, algebraic material balances are solved from the extreme to inside the distillation column, while the feed stage is located where a minimum difference with respect to the feed composition is found. The side-stream distillation column is designed with the extension of the method of minimum difference in composition. ${ }^{23}$ For the design of the Petlyuk sequence, we use a methodology based on correlations made from Pareto fronts of different mixtures and feed compositions, ${ }^{24}$ which relate the easy separation index, ESI, ESI = $\left.\left(K_{\mathrm{A}} K_{\mathrm{C}}\right) /\left(K_{\mathrm{B}} K_{\mathrm{B}}\right)\right)$, and the feed composition to calculate the interconnection flows. The compositions of the interconnection flows are estimated as a function of the easy separation index. The designs obtained with these shortcut methodologies allow one to get a feasible initial solution for the optimization process.

\section{OPTIMIZATION OF DISTILLATION SEQUENCES}

The optimization of the azeotropic distillation sequences implies the simultaneously minimization of the heat duty of the sequence, $Q_{i}$, and the number of stages in each shell, $N_{i}$. 
These variables are in conflict between them, because to minimize the heat duty, we have to increase the number of stages, and vice versa. Because of this, we chose a multiobjective stochastic technique to perform the optimization of the distillation schemes. Therefore, we have 4, 2, and 3 objectives for conventional, side-stream, and Petlyuk sequences, respectively. As result of the multiobjective optimization, we obtain a Pareto front, which is integrated for the set of solutions that are not dominated and optimums of Pareto. ${ }^{25}$ Thereby, the Pareto front consists of all optimal sequences from minimum reflux ratio to minimum number of stages along with all designs included between these objectives, which represent the best trade-off between them. Also, the purities required in each product stream must be reached. This optimization problem can be expressed as:

$$
\begin{aligned}
& \min \left(Q_{i}, N_{i}\right)=f\left(R, F_{k}, N_{\text {in }, k}, N_{\text {out }, k}, N_{\mathrm{F}}, N_{\mathrm{S}}, N_{i}\right) \\
& \text { subject to } \\
& \vec{y}_{k} \geq \vec{x}_{k}
\end{aligned}
$$

where $R$ is the reflux ratio, $F_{k}$ is the interconnection flow $k, N_{\mathrm{F}}$ is the feed stage of the sequence, $N_{\mathrm{S}}$ is the side-stream stage, $N_{\text {in }, k}$ and $N_{\text {out }, k}$ are the numbers of stage where the interconnection flow $k$ comes and goes, and the vectors $x_{k}$ and $y_{k}$ are the required and obtained purities, respectively. All of these manipulated variables are considered if they applied for each scheme.

The construction of the Pareto front of the azeotropic distillation sequences is made through a multiobjective genetic algorithm with handling constraints, ${ }^{15}$ based on the NSGA-II. ${ }^{26}$ Note that we have used a population-based method for the design of azeotropic distillation because it offers a better performance for solving multiobjective optimization problems than that obtained with a multiobjective simulated annealing. The constraints are handled with another multiobjective optimization technique, which guides the search using the concept of non dominance. ${ }^{27}$ For the optimization of the distillation sequences, the number of individuals used was 500, while the number of generations was 60,80 , and 100 for conventional sequence, side-stream column, and Petlyuk sequence, respectively. These parameters were obtained through a tuning process until there is no significant change in the Pareto front generated.

\section{CONTROL PROPERTIES ANALYSIS}

From the Pareto front, the design with the best compromise between heat duty and number of stages is chosen, for each scheme and set of adjusted parameters, to study their control properties. Ulas et al. ${ }^{28}$ and Ulas and Diwekar ${ }^{29}$ have concluded that a good dynamic behavior in distillation can only be obtained if the effects of thermodynamic uncertainties are minimized. The effect of uncertainties due to the usage of local methods during the parameter estimation step in VLE modeling propagated the dynamic response of the equipment. It results in a lower product yield and a purity that is significantly different from the specified purity on the distillate.

Hence, we highlight the importance of using good thermodynamic parameters in the design of distillation columns. This clearly impacts the dynamic response of the distillation column and its control properties, and also links the design stage with the control stage of a distillation column. We then analyze first the theoretical control properties, with singular value decomposition technique, and later the dynamic performance at closed-loop.

5.1. Theoretical Control Properties. Theoretical control properties of selected designs are evaluated using the SVD technique, which can be defined as:

$$
G=V \sum W^{H}
$$

Here, $G$ is the matrix target for SVD analysis and $\sum$ is a diagonal matrix that consists of the singular values of $G$. The singular values of the open-loop frequency function matrix of a process at a given frequency are the gains of the process at this frequency, in the directions of the corresponding input singular vectors (as the input singular vectors form a basis in the input space, the gain can be calculated in every direction). These gains play an important role when performing controllability analysis of a process, and for a complex analysis they must be evaluated in all frequency domains. The Morari Resiliency Index (MRI) is the smallest singular value $\left(\sigma^{*}\right)$ of the process open-loop frequency function matrix. The larger is its value, the more controllable is the process. If it is zero, this means that there is an input direction where the gain is zero and the matrix is not invertible. Condition number $\left(\gamma^{*}\right)$ is the ratio of the largest and smallest singular values of the process open-loop frequency function matrix. If it is large, then the matrix has strong directionality, which means that the gains vary strongly depending on input directions. Such a matrix is said to be illconditioned. A large $\gamma^{*}$ means that the system is sensitive to input and model uncertainty, and therefore the process is less controllable. Systems with higher $\sigma^{*}$ values and lower $\gamma^{*}$ are expected to show the best dynamic performance under feedback control.

5.2. Dynamic Performance at Closed-Loop. The dynamic performance at closed-loop was analyzed using the criterion of minimization of the integral of the absolute error (IAE). The control loops of the PID controller were established as follows: the composition of volatile component in distillate with reflux ratio in first column; the composition of the stream that contains the azeotrope with the reflux ratio of the second column (in case of direct conventional sequence) or with the side-stream flow (in case of side-stream column and Petlyuk sequence); and the composition of the heavy component with the heat duty of the column. Once the control loops have been established, the manipulated variable is disturbed in $0.5 \%$ of its original value. A recursive dynamic simulation process then is performed, varying integral time and gain values looking for the minimization of IAE. It is worth mentioning that each controller is analyzed separately.

\section{CASES OF STUDY}

We select as a study case the separation of two ternary mixtures: M1, integrated by acetone, isopropanol, and water, and M2, composed of methanol, isopropanol, and water. For both mixtures, the feed stream has an equimolar composition, and it is introduced as saturated liquid; the operation pressure of all sequences is 30 psia. The required purities for acetone, isopropanol, and water in their respective product stream are $0.90,0.65$, and 0.99 , while the required purities for methanol, isopropanol, and water in their respective product stream are $0.95,0.64$, and 0.99 . These sequences are designed, optimized, and controlled using two sets of adjusted parameters in the NRTL solution model; the simulation in Aspen Plus is performed in Radfrac module. 


\section{DISCUSSION OF RESULTS}

In this section, we present the analysis of the results generated in stages of parameter estimation, design, optimization, and control of the distillation sequences with adjusted parameters, corresponding to local and global optimums, for NRTL model solution, for both mixtures. From here, we will call SAP to the adjusted parameters obtained with the simulated annealing technique, and DCP to the adjusted parameters taken from the Dechema Collection.

7.1. Mixture of Acetone-Isopropanol-Water. For the mixture acetone-isopropanol-water, SAP and DCP are shown in Table 1, where we observe that binary pairs isopropanol-

Table 1. Adjusted Parameters for NRTL Model Solution from Simulated Annealing and the Dechema Collection, for the Mixture Acetone-Isopropanol-Water

\begin{tabular}{cccrr} 
& $\begin{array}{c}\text { adjusted } \\
\text { parameter }\end{array}$ & $\begin{array}{c}\text { acetone (1), } \\
\text { isopropanol (2) }\end{array}$ & $\begin{array}{c}\text { isopropanol (1), } \\
\text { water (2) }\end{array}$ & $\begin{array}{r}\text { acetone (1), } \\
\text { water (2) }\end{array}$ \\
Dechema & $\mathrm{A} 12$ & 536.7280 & 39.8541 & 750.3181 \\
Collection & $\mathrm{A} 21$ & -97.8216 & 1659.2572 & 1299.3970 \\
& $\alpha_{12}$ & 0.3018 & 0.3255 & 0.5856 \\
simulated & $\mathrm{A} 12$ & 402.8160 & 39.8541 & 750.3181 \\
annealing & $\mathrm{A} 21$ & 9634.6100 & 1659.2572 & 1299.3970 \\
& $\alpha_{12}$ & 0.4195 & 0.3255 & 0.5856 \\
\hline
\end{tabular}

water and acetone-water have exactly the same values for SAP and DCP; both binary pairs correspond to global optimums. However, remarkable differences are found in the binary pair acetone-isopropanol. For instance, the parameter A21 changes from a negative value in DCP to a positive and big value with SAP; also, the nonrandomness factor has changed. Note that the nonrandomness factor, for binary pair acetone-water, has a value of 0.5856 ; this value is higher than the suggested range defined by several authors. This observation is important because when the nonrandomness factor is used as an adjustable parameter, without restricting its values to the range suggested, the NRTL model predicts a thermodynamic behavior that matches with the experimental data. ${ }^{14}$ Nevertheless, the change in these parameters for one binary pair does not affect the prediction of the two azeotropic points presented at 30 psia, as can be seen in Table 2. Because the prediction in

Table 2. Azeotropic Points Composition with Adjusted Parameters from Simulated Annealing and Dechema Collection, for the Mixture Acetone-Isopropanol-Water

\begin{tabular}{ccccc} 
& azeotrope & $X_{\text {acetone }}$ & $X_{\text {isopropanol }}$ & $X_{\text {water }}$ \\
\hline Dechema Collection & binary 1 & 0.9606 & & 0.0394 \\
& binary 2 & & 0.6824 & 0.3176 \\
simulated annealing & binary 1 & 0.9606 & & 0.0394 \\
& binary 2 & & 0.6824 & 0.3176 \\
\hline
\end{tabular}

the azeotropic points has not changed, we calculate residue curve maps, with DCP and SAP, to compare the prediction in the entire composition space. Figure 1 shows the residue curve maps, which present just small differences between them. Considering the small differences in the prediction of phase equilibrium with DCP and SAP, we can expect minor differences in the design and control properties of the optimal designs. Once the feasibility of the separation is verified, then shortcut methodologies are used to get initial designs of all sequences.

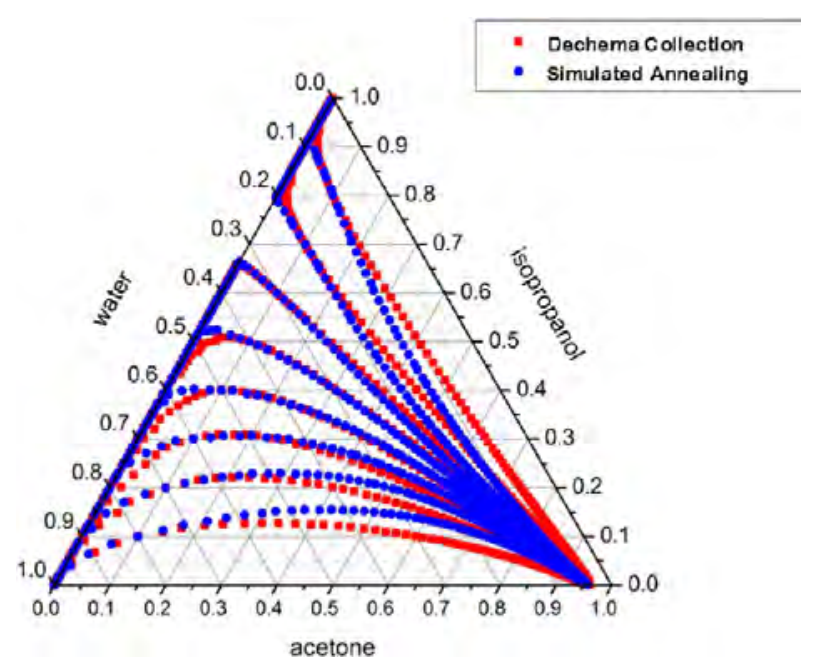

Figure 1. Residue curve map of the mixture acetone-isopropanolwater calculated with adjusted parameters from simulated annealing and the Dechema Collection.

Figure 2 shows the Pareto fronts generated for each sequence, with DCP and SAP; the objectives have been grouped into two: total number of stages and total heat duty of the sequence, for illustrative purposes. From Figure 2 we observe that for all sequences, the front generated with SAP is under the front generated with DCP. In general, optimal designs with SAP show minor energy consumptions with similar or less number of total stages, in comparison with those with DCP. From the three sequences analyzed, the Petlyuk sequence presents the minor energy consumption, followed by the side-stream column, the energy requirements of which match partially the Pareto front of the conventional direct sequence.

From these Pareto fronts, we select three designs for each sequence with the minor heat duty, the minor number of stages, and an intermediate design between these extremes. The selected designs are shown in Table 3, and they present notable differences in the heat duty, $Q$ and total number of stages, when using DCP or SAP. For the conventional direct sequence with the same number of stages, the SAP design requires $94 \%$ of the heat duty of the DCP design. This difference is small for this sequence; nevertheless, in the side-stream column for a similar number of stages, the SAP design consumes $34 \%$ of the energy consumption of the DCP design. This result is quite unexpected, considering that the prediction of the azeotropic point is the same, and minimal differences are found in the liquid-vapor equilibrium prediction. In the case of the Petlyuk sequence for a similar number of stages, the SAP design requires $80 \%$ of the energy required by DCP design. Basically, the SAP designs require $6 \%, 66 \%$, and $20 \%$ less energy than the DCP designs, in the conventional direct, side stream, and Petlyuk sequences, respectively. The found differences are huge, considering that just one binary pair does not match between DCP and SAP, and the components of this binary pair do not form azeotropes. In the number of stages we observe the same tendency, but the differences are very small. These results show that the use of global (SAP) or local (DCP) adjusted parameters significantly affects the design of conventional and thermally coupled schemes.

Moreover, these selected designs were used to analyze the theoretical control properties and the dynamic performance. It 


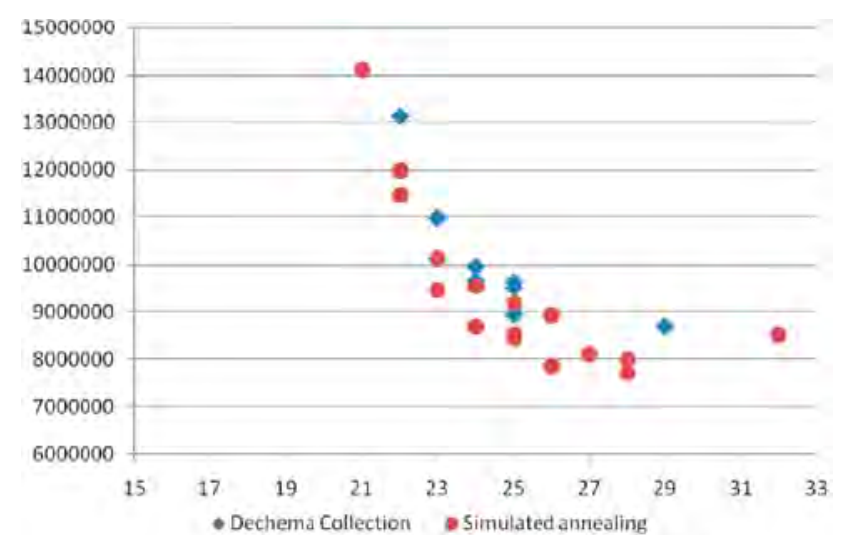

(a) Conventional direct sequence

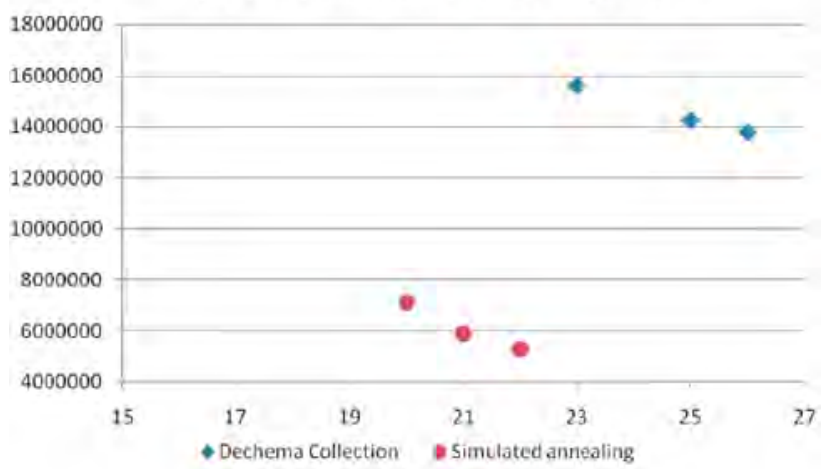

(b) Side stream distillation column

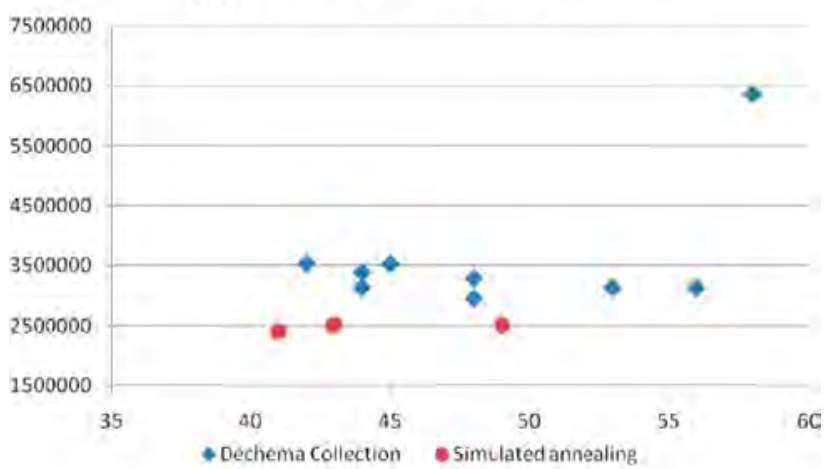

(c) Petlyuk sequence

Figure 2. Pareto fronts of (a) conventional direct sequence, (b) sidestream column, and (c) Petlyuk sequence with adjusted parameters taken from the Dechema Collection and those calculated with simulated annealing, for the mixture acetone-isopropanol-water.

is important to note that the design of the columns in the module RADFRAC (Aspen Plus) employed SAP and DCP; this file, which contains thermodynamic parameters, is exported to Aspen Dynamic. Using dynamic simulations generated either open-loop or closed-loop, we obtain the response needed to be used in the technique of singular value decomposition (the transfer function matrix generated by using step changes in the manipulated variable and recording the dynamic behavior of the three product compositions, $\mathrm{A}-\mathrm{C}$; it is worth mentioning that the dynamic responses can be adjusted to first or parallel processes) or can perform tuning of the PI controllers to generate the responses that minimize IAE criteria.

For the optimal designs, displayed in Table 3, with similar number of stages, we calculate the condition number and minimum singular values for the whole range of frequency with
Table 3. Selected Designs from the Pareto Fronts of Conventional Direct Sequence, Side-Stream Column, and Petlyuk Sequence, for the Mixture Acetone-IsopropanolWater

\begin{tabular}{|c|c|c|c|c|}
\hline & \multicolumn{2}{|c|}{ Dechema Collection } & \multicolumn{2}{|c|}{ simulated annealing } \\
\hline & $N$ & $Q \mathrm{Btu} / \mathrm{h}$ & $N$ & Q Btu/h \\
\hline \multicolumn{5}{|c|}{ Conventional Direct Sequence } \\
\hline minor heat duty & 29 & 8693037 & 28 & 7716505 \\
\hline similar number of stages & 25 & 8942546 & 25 & 8448570 \\
\hline minor number of stages & 22 & 13137574 & 21 & 14123565 \\
\hline \multicolumn{5}{|c|}{ Side-Stream Column } \\
\hline minor heat duty & 26 & 13790826 & 22 & 5309621 \\
\hline similar number of stages & 25 & 14247716 & 21 & 5902515 \\
\hline minor number of stages & 23 & 15639844 & 20 & 7121893 \\
\hline \multicolumn{5}{|c|}{ Petlyuk Sequence } \\
\hline minor heat duty & 48 & 2955292 & 41 & 2411171 \\
\hline similar number of stages & 44 & 3134434 & 43 & 2516848 \\
\hline minor number of stages & 58 & 6361508 & 49 & 2518394 \\
\hline
\end{tabular}

DCP and SAP; see Figures 3 and 4. For the conventional direct sequence, the condition number and the minimum singular values are practically the same with both sets of parameters in the whole range of the frequency. For the side-stream column, we have a similar situation, for both sets of parameters in the whole range of frequency. The principal difference is observed in the Petlyuk sequence, where the minimum condition number is low in the whole range of frequency with DCP, and at intermediate frequencies with SAP; the minimum singular value are major at low frequencies with DCP, and major at intermediate frequencies with SAP, but in a smaller interval. The graphics suggest that the Petlyuk sequence with $\mathrm{SAP}$ is more sensitive to disturbance and modeling errors and less controllable than the Petlyuk sequence with DCP.

In general, the conventional direct sequence is the less sensitive sequence for disturbances and modeling errors, and the more controllable for DCP and SAP in the whole range of frequency. A similar behavior can be expected from Petlyuk sequence when DCP is used, while the Petlyuk sequence with SAP presents worse control properties than the Petlyuk sequence with DCP. The side-stream column offers the worst conditioning properties against model uncertainties and process disturbances than the other arrangement at low frequencies, for DCP and SAP.

Tables 4 and 5 show the results obtained in a closed-loop analysis, which are consistent with those obtained from the singular value decomposition technique. The minimum values for IAE for the loops of components $\mathrm{A}$ and $\mathrm{C}$ are obtained in the optimal designs with DCP, for all sequences, while the minimum value of IAE for the loop of component $B$ is observed in optimal designs with SAP for all sequences. It is worth mentioning that the more complicated loop is that where the component B is controlled, because the azeotrope is extracted there. If we analyze the IAE for the optimal designs with DCP, we found that the minimum values for the loops of components $\mathrm{A}$ and $\mathrm{B}$ are observed in conventional direct sequence and Petlyuk sequence, while the minimum values for the loop of component $\mathrm{C}$ are observed in Petlyuk sequence and sidestream column. According to this analysis, the best scheme is the Petlyuk sequence, because it presents the best or the second best value for the minimum IAE in all control loops; the second best scheme is the conventional direct sequence, because it 

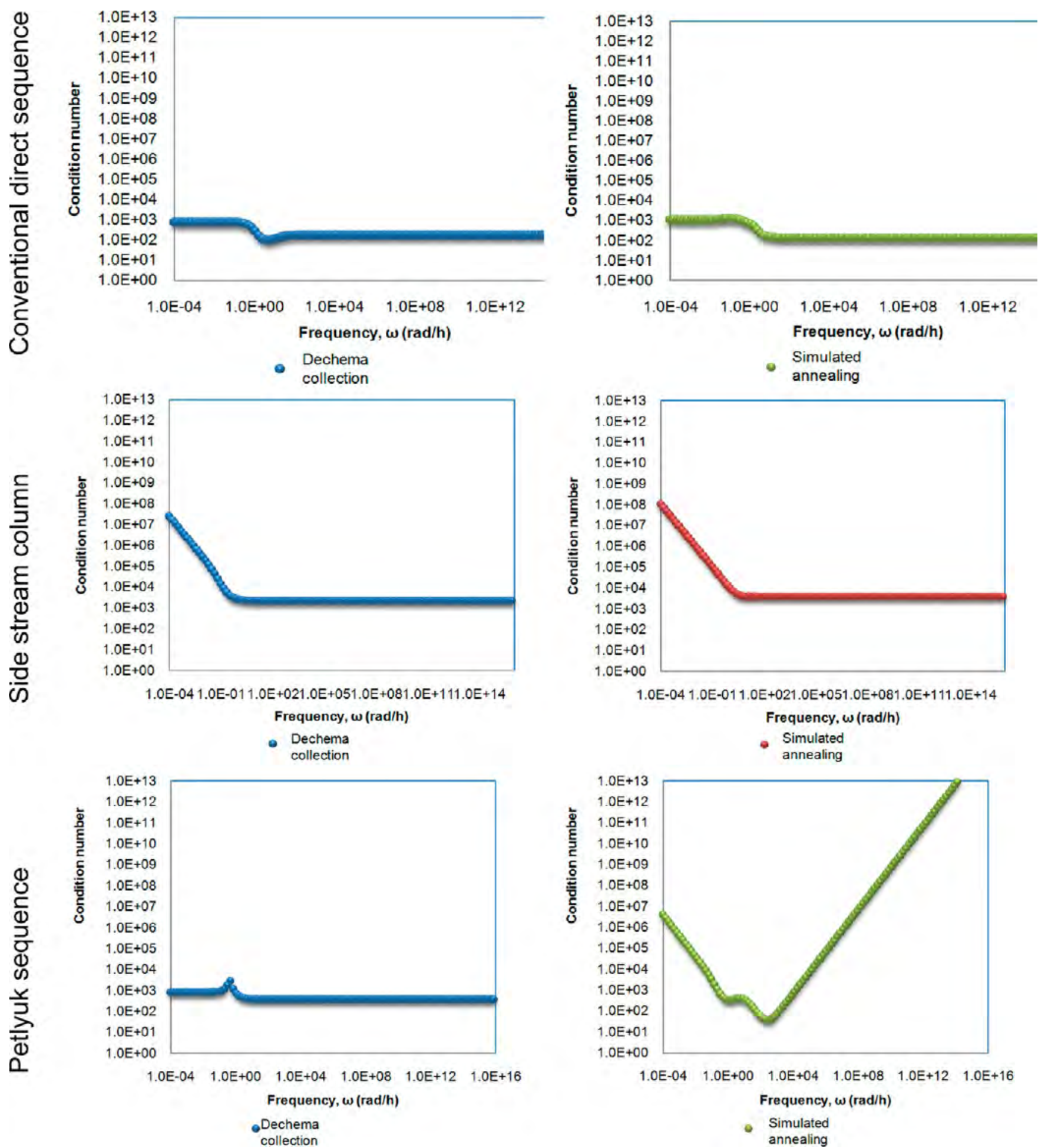

Figure 3. Condition number for selected designs with DCP and SAP, for the mixture acetone-isopropanol-water.

presents the best or the second best value for the minimum IAE in at least two control loops.

On the other hand, if we analyze the IAE for the optimal designs with $\mathrm{SAP}$, we found that the minimum values for loops of components B and C are observed in the side-stream column and Petlyuk sequence, while the minimum values for loop of component $\mathrm{A}$ is observed in conventional direct sequence and side-stream column. According to this analysis, the best scheme is the side-stream column, because it presents the best or the second best value for the minimum IAE in all control loops; the second best scheme is the Petlyuk sequence, because it presents the best or the second best value for the minimum IAE in at least two control loops.

As can be seen, for this case the conclusions are slightly different. If we use DCP, the best sequences are the Petlyuk sequence and the conventional direct sequence; if we use SAP, the best sequences are the side-stream column and the Petlyuk sequence. An important point to emphasize is that according to 

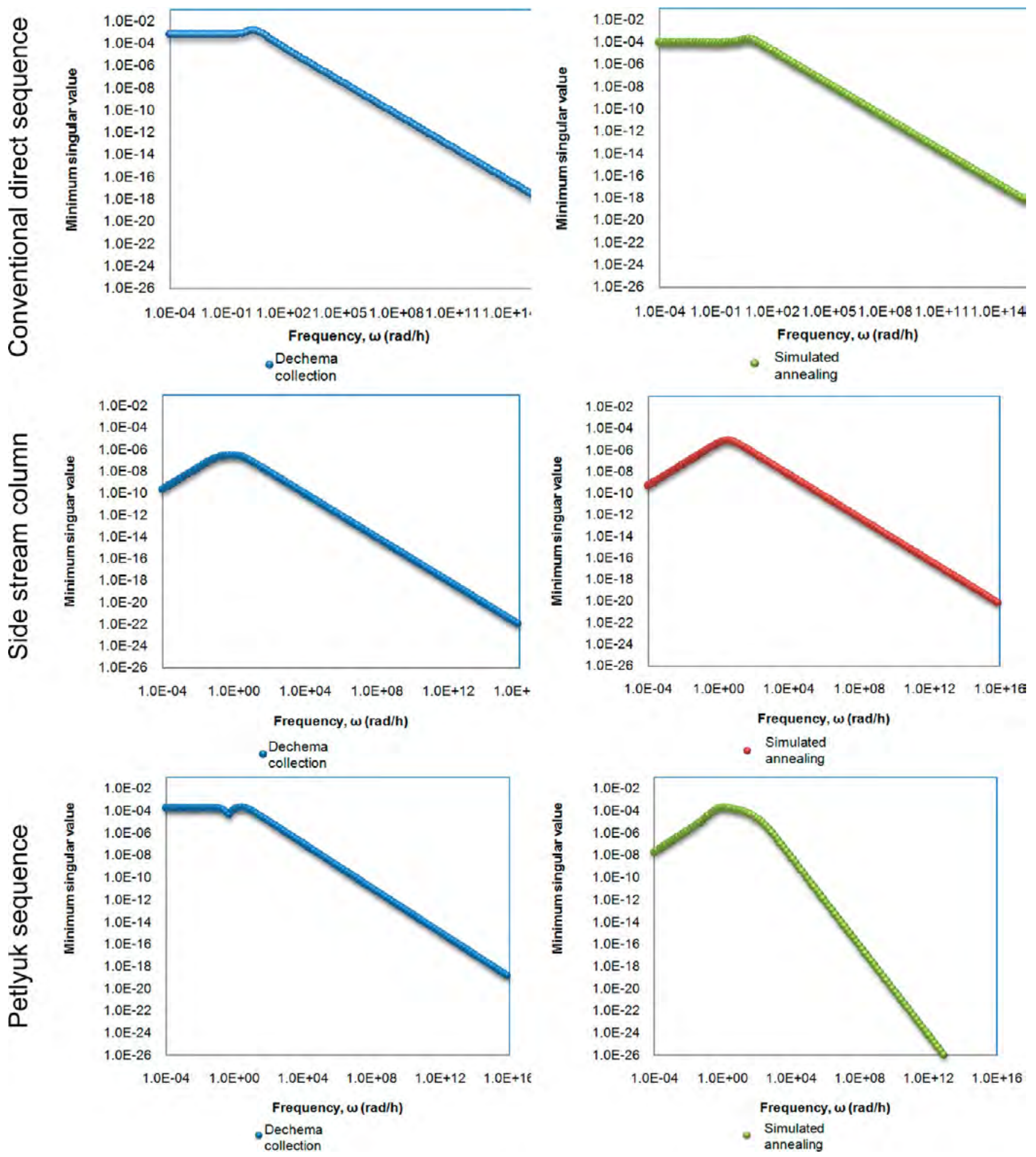

Figure 4. Minimum singular value for selected designs with DCP and SAP, for the mixture acetone-isopropanol-water.

Table 3, the Petlyuk sequence has the minimum energy requirement in the designs generated with DCP and SAP. However, the Petlyuk column designed using DCP shows slightly better control properties (minimum IAE values in all control loops) under open- and closed-loop analysis than the Petlyuk column using SAP (minimum IAE values in two control loops).

In brief, the use of adjusted parameters, corresponding to a global optimum, leads to optimal designs with minor energy requirements, for similar or less number of total stages, in comparison with optimal designs calculated with local adjusted parameters. This is due to that the global adjusted parameters reproduce better the experimental data, improving the prediction of phase equilibrium. With a better representation of phase equilibrium, we can generate adequate designs, avoiding oversizing the equipment. Also, the control properties under open and closed analysis can be considered as similar. 
Table 4. Integral Absolute Error (IAE) Values for Selected Designs with Adjusted Parameters from the Dechema Collection, for the Mixture Acetone-Isopropanol-Water

\begin{tabular}{lccc} 
sequence & $\begin{array}{c}\text { IAE, light } \\
\text { component loop }\end{array}$ & $\begin{array}{c}\text { IAE, intermediate } \\
\text { component loop }\end{array}$ & $\begin{array}{c}\text { IAE, heavy } \\
\text { component loop }\end{array}$ \\
$\begin{array}{c}\text { conventional } \\
\text { side-stream } \\
\text { column }\end{array}$ & $1.35 \times 10^{-5}$ & $3.30 \times 10^{-5}$ & $2.01 \times 10^{-5}$ \\
$\begin{array}{c}\text { Petlyuk } \\
\text { sequence }\end{array}$ & $2.84 \times 10^{-6}$ & $3.29 \times 10^{-4}$ & $2.14 \times 10^{-6}$ \\
\hline
\end{tabular}

Table 5. Integral Absolute Error (IAE) Values for Selected Designs with Adjusted Parameters from Simulated Annealing, for the Mixture Acetone-Isopropanol-Water

\begin{tabular}{cccc} 
sequence & $\begin{array}{c}\text { IAE, light } \\
\text { component loop }\end{array}$ & $\begin{array}{c}\text { IAE, intermediate } \\
\text { component loop }\end{array}$ & $\begin{array}{c}\text { IAE, heavy } \\
\text { component loop }\end{array}$ \\
$\begin{array}{c}\text { conventional } \\
\text { side-stream } \\
\text { column }\end{array}$ & $1.40 \times 10^{-5}$ & $3.28 \times 10^{-5}$ & $2.02 \times 10^{-5}$ \\
$\begin{array}{c}\text { Petlyuk } \\
\text { sequence }\end{array}$ & $3.23 \times 10^{-5}$ & $2.16 \times 10^{-5}$ & $9.97 \times 10^{-6}$ \\
\hline
\end{tabular}

7.2. Mixture of Methanol-Isopropanol-Water. The SAP and DCP for the mixture methanol-isopropanol-water are shown in Table 6, where we observe that the adjusted parameters in the binary pair isopropanol-water have exactly the same values. On the other hand, remarkable differences are found in the binary pairs methanol-isopropanol and methanol-water. In the binary pair methanol-isopropanol, the parameter A21 changes from a negative value, DCP, to a positive and big value, SAP; a similar situation occurs in parameter A12 of the binary pair methanol-water. However, the observed changes in the nonramdomness factors of both binary pairs attract the most attention: their values are considerably higher than the suggested range defined by several authors; this observation is important because when the nonrandomness factor is used as adjustable parameter, without restricting its values to the range suggested, the NRTL model predicts a thermodynamic behavior that matches with the experimental data. ${ }^{14}$ Nevertheless, the change in these parameters does not affect the calculated composition of the azeotropic point presented at 30 psia, as can be seen in Table 7 . Because the prediction in the azeotropic points has not changed, we calculate residue curve maps with DCP and SAP to compare the prediction in the entire composition space. Figure 5 shows the residue curve maps, which present just small differences between them. Considering that the azeotropic point's compositions are the same, and there are just light differences in the residue curve maps, we expect minor differences in the design and control properties of the optimal designs.
Table 7. Azeotropic Points Composition with Adjusted Parameters from Simulated Annealing and the Dechema Collection, for the Mixture Methanol-Isopropanol-Water

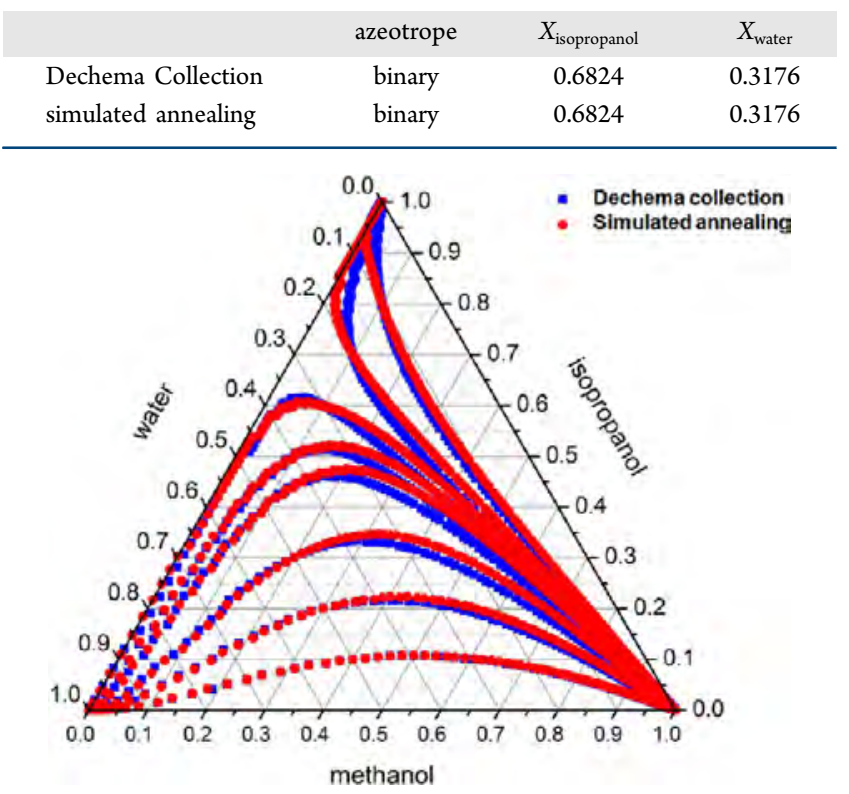

Figure 5. Residue curve map of the mixture methanol-isopropanolwater calculated with adjusted parameters from simulated annealing and the Dechema Collection.

Once the feasibility of the proposed separation is verified, then the shortcut methodologies are used to get initial designs of all sequences, including a dividing wall column, for the optimization strategy.

Figure 6 shows the Pareto fronts generated for each sequence with DCP and SAP, where we observe that for all sequences, the front generated with SAP is under the front generated with DCP. In general, optimal designs with SAP have minor energy consumptions in comparison with the optimal designs with DCP; these lower values are accompanied by similar or less number of total stage in the sequence. From the four sequences analyzed, it can be seen that the dividing wall column presents minor energy consumption followed very close by the Petlyuk sequence; after them, we have the conventional direct sequence, for which maximum energy requirements match partially the Pareto front of the side-stream column.

From these Pareto fronts, we select three designs for each sequence with the minor heat duty, the minor number of stages, and an intermediate design between these extremes. The selected designs, shown in Table 8, present notable differences in the heat duty, $Q$ and total number of stages, when using DCP or SAP. For the conventional direct sequence, with the same number of stages the SAP design requires $89 \%$ of the heat

Table 6. Adjusted Parameters for NRTL Model Solution from Simulated Annealing and the Dechema Collection, for the Mixture Methanol-Isopropanol-Water

\begin{tabular}{rcrrr} 
& adjusted parameter & methanol (1), isopropanol (2) & isopropanol (1), water (2) & methanol (1), water (2) \\
Dechema Collection & A12 & 219.5610 & 39.8541 & -48.6725 \\
& A21 & -250.9962 & 1659.2572 & 610.4032 \\
\multirow{2}{*}{ simulated annealing } & $\alpha_{12}$ & 0.3047 & 0.3255 & 0.3001 \\
& A12 & -95.0591 & 39.8541 & 163.2375 \\
& A21 & 1260.3568 & 1659.2572 & 427.5462 \\
$\alpha_{12}$ & 1.8626 & 0.3255 & 0.7686
\end{tabular}




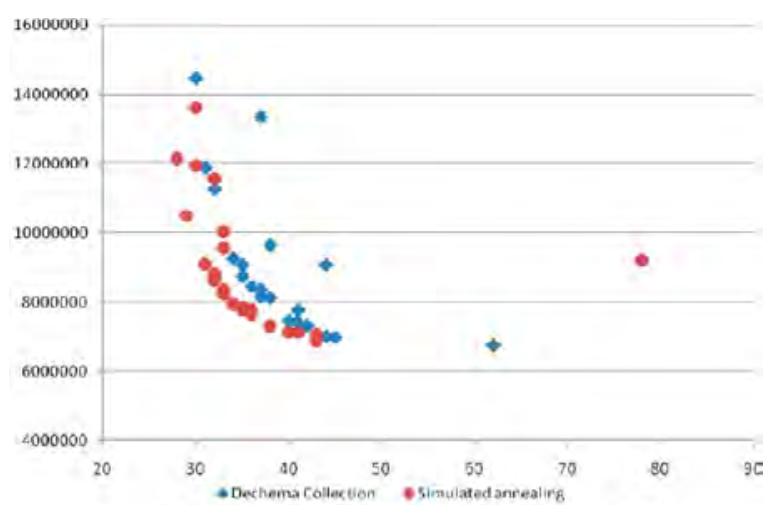

(a) Conventional direct sequence

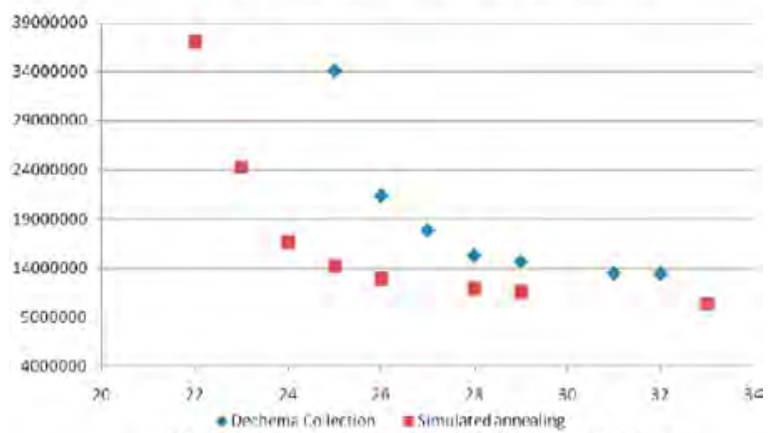

(b) Side stream distillation column

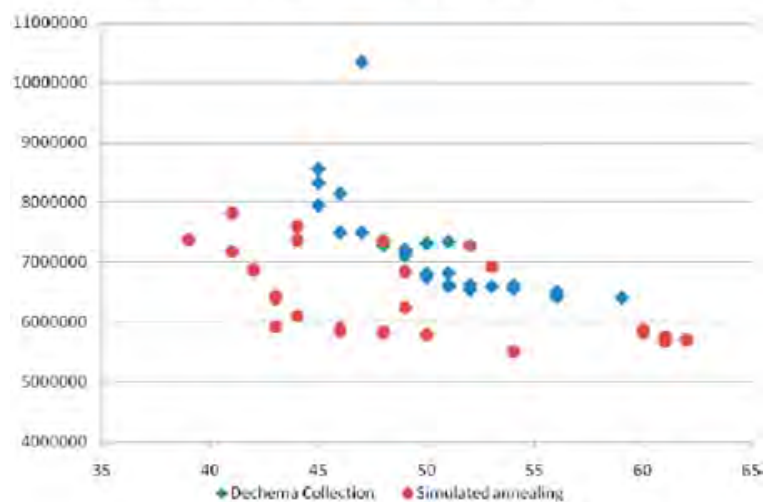

(c) Petlyuk sequence

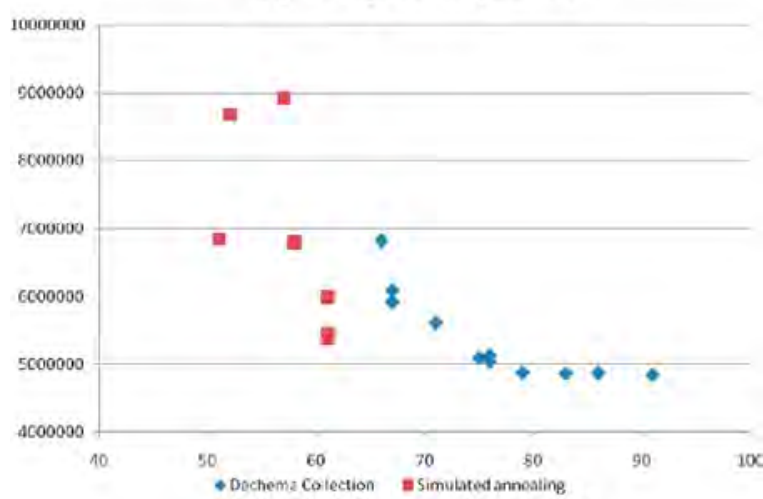

(d) Dividing wall column

Figure 6. Pareto fronts of (a) conventional direct sequence, (b) sidestream column, and (c) Petlyuk sequence with adjusted parameters taken from the Dechema Collection and those calculated with simulated annealing, for the mixture methanol-isopropanol-water.

duty of the DCP design. This difference is significant for this sequence; nevertheless, in the side-stream column for a similar
Table 8. Selected Designs from the Pareto Fronts of Conventional Direct Sequence, Side-Stream Column, and Petlyuk Sequence, for the Mixture Methanol-IsopropanolWater

\begin{tabular}{|c|c|c|c|c|}
\hline & \multicolumn{2}{|c|}{ Dechema Collection } & \multicolumn{2}{|c|}{ simulated annealing } \\
\hline & $N$ & $Q \mathrm{Btu} / \mathrm{h}$ & $N$ & $Q$ Btu/h \\
\hline \multicolumn{5}{|c|}{ Conventional Direct Sequence } \\
\hline minor heat duty & 62 & 6763069 & 43 & 6882831 \\
\hline similar number of stages & 38 & 8133277 & 38 & 7306284 \\
\hline minor number of stages & 30 & 14483618 & 30 & 13621172 \\
\hline \multicolumn{5}{|c|}{ Side-Stream Column } \\
\hline minor heat duty & 32 & 13415186 & 33 & 10376497 \\
\hline similar number of stages & 28 & 15287353 & 28 & 11917980 \\
\hline minor number of stages & 25 & 34141276 & 22 & 37054652 \\
\hline \multicolumn{5}{|c|}{ Petlyuk Sequence } \\
\hline minor heat duty & 59 & 6412989 & 54 & 5508571 \\
\hline similar number of stages & 53 & 6596043 & 53 & 6921930 \\
\hline minor number of stages & 47 & 10353573 & 41 & 7821727 \\
\hline \multicolumn{5}{|c|}{ Dividing Wall Column } \\
\hline minor heat duty & 91 & 4840141 & 61 & 5385033 \\
\hline similar heat duty & 67 & 6087828 & 61 & 5995038 \\
\hline minor number of stages & 66 & 6821949 & 57 & 8920228 \\
\hline
\end{tabular}

number of stages, the SAP design consumes just $77 \%$ of the energy consumption of the DCP design. The found differences are meaningful, considering that prediction of the azeotropic point is the same, and minimal differences are found in the liquid-vapor equilibrium prediction. For the dividing wall column with a similar number of stages, the SAP design requires $98 \%$ of the energy required by DCP design. Basically, the SAP designs require $11 \%, 33 \%$, and $2 \%$ less energy than the DCP designs, in the conventional direct, side-stream, and dividing wall column, respectively. The found differences in heat duties are huge, while in the number of stages we observe the same tendency, but the differences are very small. These results show that the use of global (SAP) or local (DCP) adjusted parameters significantly affects the results in design, simulation, and optimization of conventional and thermally coupled schemes.

The selected designs, which are shown in Table 8, were used to analyze the theoretical control properties and the dynamic performance. After the optimal designs were obtained, openloop dynamic simulations were carried out in Aspen Dynamics to obtain the transfer function matrix. For the case study considered here, the transfer function matrix was generated by using step changes in the manipulated variable and recording the dynamic behavior of the three product compositions (AC). It is worth mentioning that the dynamic responses can be adjusted to first or parallel processes.

For the optimal designs displayed in Table 8 with similar number of stages, we calculate the condition number and minimum singular values for the whole range of frequencies with DCP and SAP, Figures 7 and 8 . In the conventional direct sequence, we observed that the optimal designs with SAP present the smallest condition number and the greater minimum singular values, in the whole range of the frequency. For the side-stream column, we observed a smaller condition number for the designs with DCP, but slightly major minimum singular values in the design with SAP, in the whole range of frequency. For the Petlyuk sequence and the dividing wall column, we observe that the optimal designs with SAP present the minor condition number and the greater minimum singular 

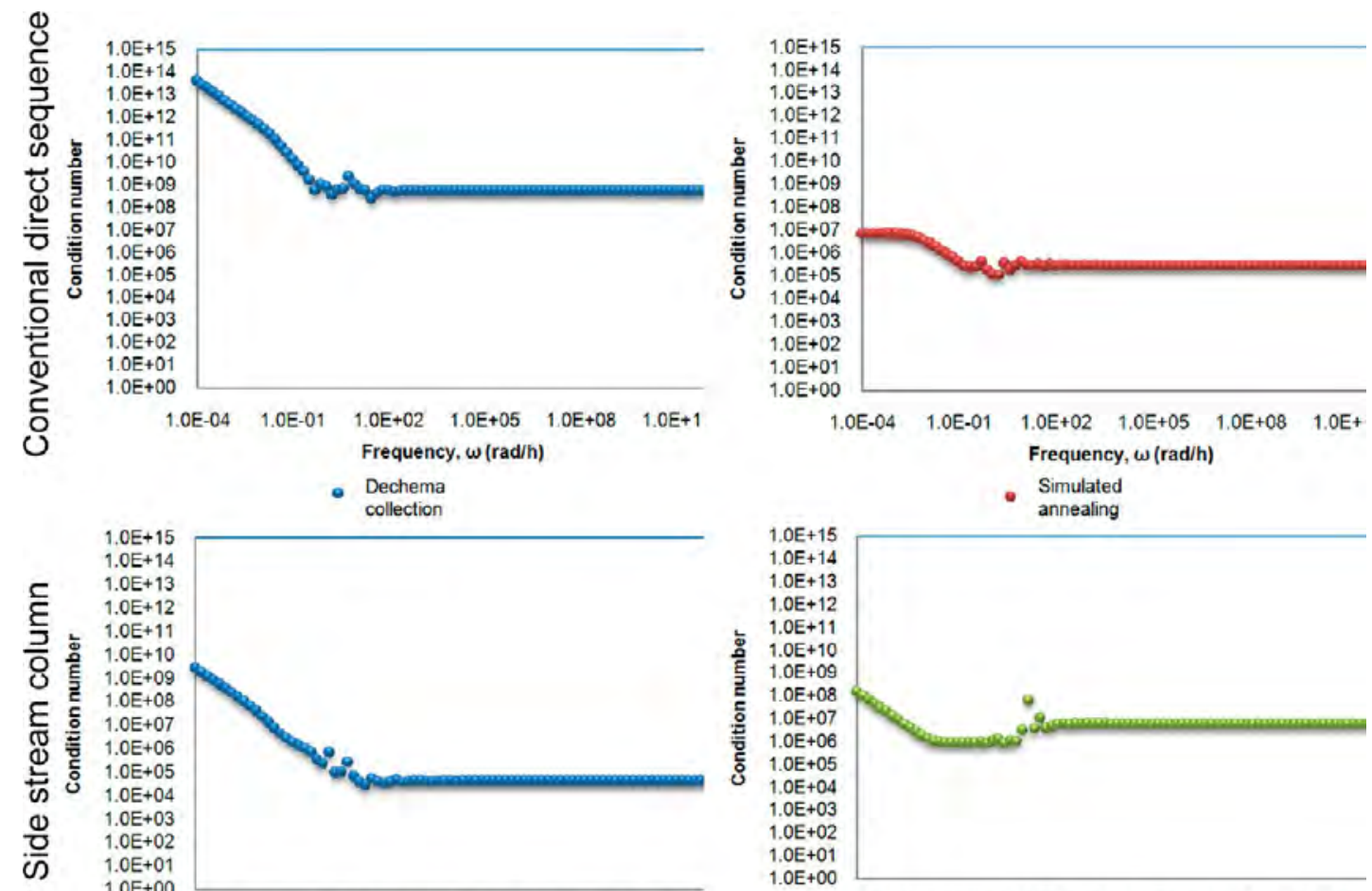

1.0E-041.0E-021.0E+001.0E+021.0E+041.0E+061.0E+081.0E+1 Frequency, $\omega(\mathrm{rad} / \mathrm{h})$

- Dechema
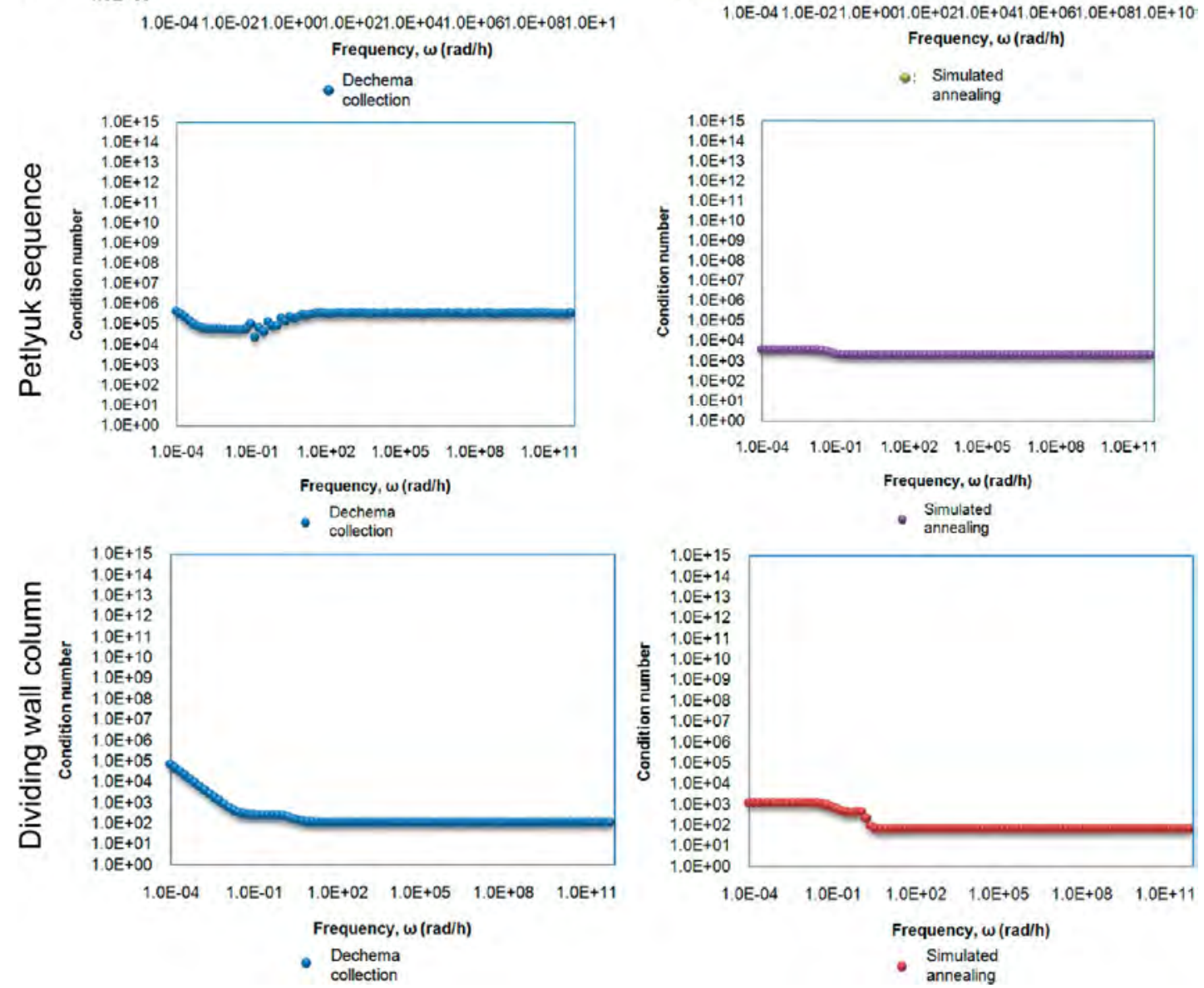

Figure 7. Condition number for selected designs with DCP and SAP, for the mixture methanol-isopropanol-water.

value. These graphics suggest that the dividing wall column and the Petlyuk sequence with SAP are less sensitive to disturbance and modeling errors and less controllable than the dividing wall column and the Petlyuk sequence with DCP. Similar control properties can be expected for side-stream column for both sets of parameters, while better control properties are expected for conventional direct sequence with SAP in comparison to that with DCP. 

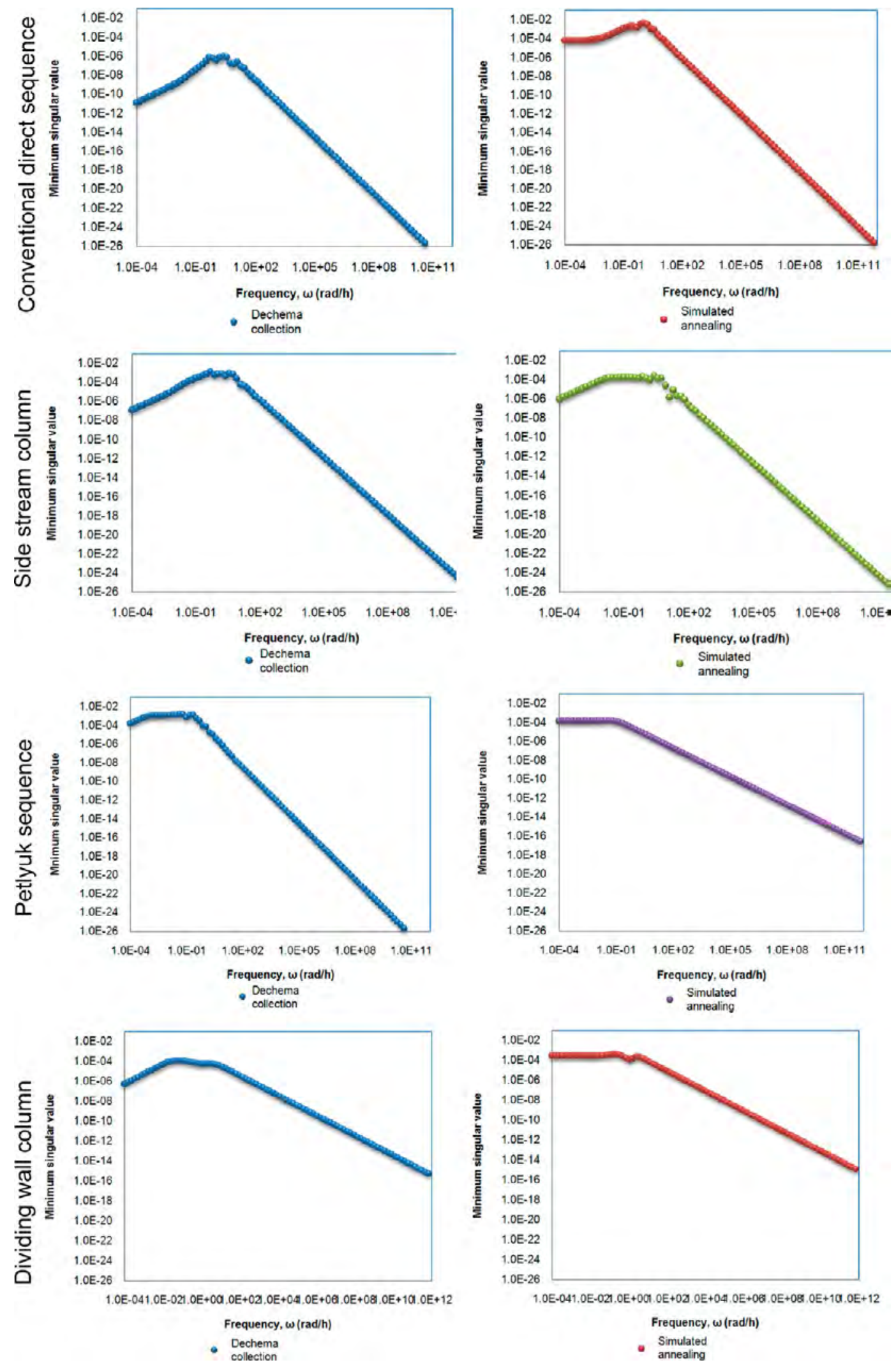

Figure 8. Minimum singular value for selected designs with DCP and SAP, for the mixture methanol-isopropanol-water.

In general, the dividing wall column is the less sensitive sequence for disturbances and modeling errors, and the more controllable for DCP and SAP in the whole range of frequency. A similar behavior can be expected from the Petlyuk sequence when SAP is used, while the Petlyuk sequence with DCP presents slightly worst control properties than the Petlyuk sequence with SAP. In this case, the conventional direct sequence offers the worst conditioning properties against 
model uncertainties and process disturbances than the other arrangement at low frequencies for DCP, while with SAP the worst conditioning properties are presented by the side-stream column.

Tables 9 and 10 show the results obtained in a closed-loop analysis, which are consistent with those obtained from the

Table 9. Integral Absolute Error (IAE) Values for Selected Designs with Adjusted Parameters from the Dechema Collection, for the Mixture Methanol-Isopropanol-Water

\begin{tabular}{lccc} 
sequence & $\begin{array}{c}\text { IAE, light } \\
\text { component loop }\end{array}$ & $\begin{array}{c}\text { IAE, intermediate } \\
\text { component loop }\end{array}$ & $\begin{array}{c}\text { IAE, heavy } \\
\text { component loop }\end{array}$ \\
$\begin{array}{c}\text { conventional } \\
\text { side-stream } \\
\text { column }\end{array}$ & $1.64 \times 10^{-5}$ & $3.31 \times 10^{-5}$ & $2.25 \times 10^{-5}$ \\
$\begin{array}{c}\text { Petlyuk } \\
\text { sequence }\end{array}$ & $2.52 \times 10^{-5}$ & $1.12 \times 10^{-4}$ & $2.30 \times 10^{-5}$ \\
$\begin{array}{c}\text { dividing wall } \\
\text { column }\end{array}$ & $4.14 \times 10^{-5}$ & $5.69 \times 10^{-5}$ & $7.17 \times 10^{-6}$ \\
\hline
\end{tabular}

Table 10. Integral Absolute Error (IAE) Values for Selected Designs with Adjusted Parameters from Simulated Annealing, for the Mixture Methanol-Isopropanol-Water

\begin{tabular}{lccc} 
sequence & $\begin{array}{c}\text { IAE, light } \\
\text { component loop }\end{array}$ & $\begin{array}{c}\text { IAE, intermediate } \\
\text { component loop }\end{array}$ & $\begin{array}{c}\text { IAE, heavy } \\
\text { component loop }\end{array}$ \\
$\begin{array}{c}\text { conventional } \\
\text { side-stream } \\
\text { column }\end{array}$ & $1.95 \times 10^{-5}$ & $2.20 \times 10^{-5}$ & $1.78 \times 10^{-5}$ \\
$\begin{array}{c}\text { Petlyuk } \\
\text { sequence }\end{array}$ & $2.89 \times 10^{-5}$ & $9.35 \times 10^{-5}$ & $2.46 \times 10^{-6}$ \\
$\begin{array}{c}\text { dividing wall } \\
\text { column }\end{array}$ & $3.00 \times 10^{-5}$ & $3.08 \times 10^{-5}$ & $7.78 \times 10^{-6}$ \\
\hline
\end{tabular}

singular value decomposition technique. In general, the minimum values for IAE for the loops of components $\mathrm{B}$ and $\mathrm{C}$ are obtained in the optimal designs with SAP, for three sequences, while the minimum value of IAE for loop of component $\mathrm{A}$ is observed in optimal designs with $\mathrm{DCP}$ for three sequences too. It is worth mentioning that the more complicated loop is that where component B is controlled, because the azeotrope is extracted there; again, this control loop has minor IAE values when SAP is used, as in the first analyzed case.

If we analyze the IAE for the optimal designs with DCP, we found that the minimum values for loops of components $\mathrm{A}, \mathrm{B}$, and $C$ are observed in the side-stream column, conventional direct sequence, and dividing wall column, respectively. In the optimal designs with SAP, the minimum values for loops of components $\mathrm{A}$ and $\mathrm{C}$ are observed in the side-stream column, while the loop of component $B$ has the minimum value in the conventional direct sequence. According to this analysis, in general the minimum values of IAE are observed in the conventional direct sequence and the dividing wall column with SAP and DCP.

An important point to highlight is that according to Table 3, design with minimum energy requirement in the designs generated with DCP and SAP is the dividing wall column. Additionally, the dividing wall column shows good control properties under open- and closed-loop analysis. For this particular case of study, the design of dividing wall column is independent of the parameters used in the thermodynamic model, because in both cases the best option is dividing wall configuration.

\section{CONCLUDING REMARKS}

A formal analysis to study the effect of the adjusted parameters of model NRTL on the design, optimization, and control of azeotropic sequences has been presented. Results show that the use of global adjusted parameters leads to optimal designs with minor energy requirements, for similar or less number of total stages, in comparison with optimal designs calculated with local adjusted parameters. Also, the control properties under open and closed analysis are slightly better when optimal adjusted parameters are used. Despite that some discrepancies in the designs with both sets of parameters were expected, results show that small differences in the phase equilibrium analysis are translated and maximized in the later stages of design, optimization, and control. This is due to that the global adjusted parameters reproduce better the experimental data, improving the prediction of phase equilibrium. With a better representation of phase equilibrium, we can generate adequate designs, avoiding oversizing the equipment. For the analyzed cases, the energy consumptions differ until $66 \%$, even when the prediction of azeotropic points does not change. Also, the control properties deteriorate slightly just by changing the parameters used.

The huge variation in energy savings and slightly differences in control properties represent a serious problem, because new separation schemes and/or improvement of existing plants are evaluated through design and control studies, principally, and they determine if the structure or improvement can be implemented in practical applications.

\section{AUTHOR INFORMATION}

\section{Corresponding Author}

*Tel.: (+52) 442192 1200; (+52) 44232993 48. E-mail: claugtez@gmail.com.

\section{Notes}

The authors declare no competing financial interest.

\section{ACKNOWLEDGMENTS}

Financial support provided by CONACyT (México) through project 84552 is gratefully acknowledged.

\section{REFERENCES}

(1) Doherty, M. F.; Malone, M. F. Conceptual Design of Distillation Systems; McGraw-Hill: New York, 2001.

(2) Gutiérrez-Antonio, C.; Iglesias-Silva, G. A.; Jiménez-Gutiérrez, A. Effect of different thermodynamic models on the design of homogeneous azeotropic distillation columns. Chem. Eng. Commun. 2007, 195, 1059.

(3) Ulas, S.; Diwekar, U. M.; Stadtherr, M. A. Uncertainties in parameter estimation and optimal control in batch distillation. Comput. Chem. Eng. 2005, 29, 1805.

(4) Gau, C-Y; Brennecke, J. F.; Stadtherr, M. A. Reliable nonlinear parameter estimation in VLE modeling. Fluid Phase Equilib. 2000, 168, 1 .

(5) Frenkel, M.; Chirico, R. D.; Diky, V.; Muzny, C.; Dong, Q.; Marsh, K. N.; Dymond, J. H.; Wakeham, W. A.; Stein, S. E.; Königsberger, E.; Goodwin, A. R. H.; Magee, J. W.; Thijssen, M.; Haynes, W. M.; Watanasari, S.; Satyro, M.; Schmidt, M.; Johns, A. I.; Hardin, G. R. New global communication process in thermodynamics: impact on quality of published experimental data. J. Chem. Inf. Model. 2006, 46, 2487.

(6) Reed, M. E.; Whiting, W. B. Sensitivity and uncertainty of process designs to thermodynamic model parameters: A Monte Carlo approach. Chem. Eng. Commun. 1993, 124, 39. 
(7) Vasquez, V. R.; Whiting, W. B. Effect of systematic and random errors in Thermodynamic models on chemical process design and simulation: a Monte Carlo approach. Ind. Eng. Chem. Res. 1999, 38, 3036.

(8) Vasquez, V. R.; Whiting, W. B. Uncertainty and sensitivity analysis of thermodynamic models using equal probability sampling (EPS). Comput. Chem. Eng. 2000, 23, 1825.

(9) Xin, Y.; Whiting, W. B. Case studies of computer-aided design sensitivity to thermodynamic data and models. Ind. Eng. Chem. Res. 2000, 39, 2998.

(10) Xin, Y.; Vasquez, V. R.; Whiting, W. B. Effect of regression approach in the estimation of nonlinear model parameters on process design and simulation: applications to kinetic and thermodynamic models. Comput. Chem. Eng. 2000, 24, 1269.

(11) Vidaurre, G.; Vasquez, V. R.; Whiting, W. B. Robustness of nonlinear regression methods under uncertainty: Applications in chemical kinetics models. Ind. Eng. Chem. Res. 2004, 43, 1395.

(12) Doherty, M. F.; Okasinski, M. J. Thermodynamic behavior of reactive azeotropes. AIChe J. 2004, 43, 2227.

(13) Gutiérrez-Antonio, C.; Bonilla-Petriciolet, A.; SegoviaHernández, J. G.; Briones-Ramírez, A. Data correlation in homogeneous azeotropic mixtures using NRTL model and stochastic optimization methods. In Proceedings of 24th European Symposium on Applied Thermodynamics (ESAT); Arce, A., Soto, A., Eds.; 2009; ISBN: 978-84-692-2664-3, p 154.

(14) Bonilla-Petriciolet, A.; Iglesias-Silva, G. A.; Hall, K. R. Calculation of homogeneous azeotropes in reactive and non reactive mixtures using a stochastic optimization approach. Fuid Phase Equilib. 2009, 281, 22.

(15) Gutiérrez-Antonio, C.; Briones-Ramírez, A. Pareto front of ideal Petlyuk sequences using a multiobjective genetic algorithm with constraints. Comput. Chem. Eng. 2009, 33, 454.

(16) Bonilla-Petriciolet, A.; Bravo-Sánchez, U. I.; Castillo-Borja, F.; Zapiain-Salinas, J. G.; Soto-Bernal, J. J. The performance of simulated annealing in parameter estimation for vapor-liquid equilibrium modeling. Braz. J. Chem. Eng. 2008, 25, 409.

(17) Bollas, G. M.; Barton, P. I.; Mitsos, A. Bilevel optimization formulation for parameter estimation in vapor-liquid(-liquid) phase equilibrium problems. Chem. Eng. Sci. 2009, 64, 1768.

(18) Alvarez, V. H.; Larico, R.; Ianos, Y.; Aznar, M. Parameter estimation for vle calculation by global minimization: genetic algorithm. Braz. J. Chem. Eng. 2008, 25, 409.

(19) Goffe, B.; Ferrier, G.; Rogers, J. Global optimization of statistical functions with simulated annealing. J. Econometrics 1994, 60, 65.

(20) Corana, A.; Marchesi, M.; Martini, C.; Ridella, S. Minimizing multimodal functions of continuos variables with the simulated annealing algorithm. ACM Trans. Math. Software 1987, 13, 262.

(21) Esposito, W. R.; Floudas, C. A. Global optimization in parameter estimation of nonlinear algebraic models via the error-invariable approach. Ind. Eng. Chem. Res. 1998, 37, 1841.

(22) Gutierrez-Antonio, C.; Jiménez-Gutiérrez, A. Method for the design of azeotropic distillation columns. Ind. Eng. Chem. Res. 2007, 46, 6635.

(23) Gutiérrez-Antonio, C.; Jiménez-Gutiérrez, A. Design of sidestream azeotropic distillation columns. Chem. Eng. Res. Des. 2007, 85, 1384.

(24) Gutiérrez-Antonio, C.; Briones-Ramírez, A. Optimal design methodology for dividing wall columns. Proceedings of Distillation and Absorption; 2010; ISBN 978-90-386-2215-6, p 389.

(25) Mezura-Montes, E. Uso de la técnica multiobjetivo NPGA para el manejo de restricciones en Algoritmos Genéticos, Maestria en Inteligencia Artificial; Universidad Veracruzana: Xalapa, Veracruz, Mexico, 2001.

(26) Deb, K.; Agrawal, S.; Pratap, A.; Meyarivan, T. A fast elitist nondominated sorting genetic algorithm for multiobjective-optimization: NSGA-II, KanGAL report 200001; Indian Institute of Technology: Kanpur, India, 2000.

(27) Coello-Coello, C. A. Constraint-handling using an evolutionary multiobjective optimization technique. Civ. Eng. Environ. Syst. 2000, 17, 319 .
(28) Ulas, S.; Diwekar, U. M. Thermodynamic uncertainties in batch processing and optimal control. Comput. Chem. Eng. 2004, 28, 2245.

(29) Ulas, S.; Diwekar, U. M.; Stadtherr, M. A. Uncertainties in parameter estimation and optimal control in batch distillation. Comput. Chem. Eng. 2005, 29, 1805. 